\title{
Research on Hybrid Learning Based on Cloud Platform
}

\author{
Zhihua Wen \\ East District Staff College in Beijing \\ wzhredhair@163.com
}

Keywords: cloud platform; hybrid learning; adult education

\begin{abstract}
As cloud computing makes online learning more personalized, convenient and low-cost, the cloud platform application research in education and teaching has also become a hot topic. From the perspective of theoretical analysis, this paper discusses the concepts of cloud platform and hybrid learning, as well as the characteristics of developing hybrid learning based on cloud platform in adult colleges and universities. The purpose of this paper is to provide relevant theoretical guidance for adult education teaching in the intelligent environment supported by Internet and cloud technology.
\end{abstract}

\section{Introduction}

The "China's 13th Five-Year Plan for ICT in Education (2016)" has put forward that by 2020, we should basically build an educational information system that is "everyone can learn, everywhere can learn, always can learn", and which is suitable for the goal of the development of national education modernization. It is also pointed out more concretely that continuing education should establish a hybrid teaching mode which combines on-line and off-line, and provides convenient, flexible and individualized learning conditions for all people and lifelong learning.

Adult college students use their spare time to study, and the combination of online learning and face-to-face teaching is bound to become an efficient way for students to learn.At the same time, the construction and application of cloud computing environment make the teaching work of adult education more open and flexible, ensure the smooth development of mixed learning, and effectively solve the contradiction between working and learning in adult colleges and universities. The deep-level self-learning of students is realized, and the learning efficiency and teaching quality of students are improved. Therefore, the research of hybrid learning based on cloud platform in adult colleges and universities has become one of the important subjects in the reform of adult education.

\section{Overview of Cloud Computing, Cloud Platform and Hybrid Learning}

\subsection{Cloud computing}

Cloud computing is considered to be the third wave of information technology development, its greatest value is greatly reduced the cost of services, and its popular definition is: cloud computing is a virtualized resource pool that is invoked on demand. It distributes computing tasks in the resource pool, which enables various application systems to obtain various software services, 
computing power and storage space according to their needs. Cloud computing is not a new technology, but a service, a new model to meet the needs of customers.

Cloud computing has its inherent characteristics of low cost deployment, efficient resource application, thin client access and so on. It has broad application prospects in the field of education and greatly reduced the threshold of school information construction. So that the schools through service outsourcing and other channels to develop near "zero-cost" information have became possible.

\subsection{Cloud platform}

With the emergence of various cloud services, it has become a major trend for all industries to apply cloud services or build corresponding cloud platforms according to their own needs in order to optimize various existing models. For example: Amazon's elastic computing cloud,

IBM "Blue Cloud" computing platform and Zoho’s Baihui Cloud Platform, etc. These cloud computing platforms not only save the cost for users, but also accelerate the speed of information processing and improve work efficiency.

Under the background of cloud computing, education and teaching units do not need to develop learning platform independently. Entering cloud service platform through the Internet and using the services provided by cloud service platform, can realize uninterrupted access at any time and anywhere. It also shares bandwidth and computing resources with other users on the platform.

\subsection{Hybrid learning}

Singh \& Reed believes that hybrid learning is that" in the ' appropriate' time and through the application of 'appropriate' learning techniques to fit with 'appropriate' learning styles. And pass the ' appropriate' skills to ' appropriate' learners so as to achieve a learning style with optimized learning effects". Professor He Kekang believes that hybrid learning is to combine the advantages of traditional learning and digital networked learning. Professor $\mathrm{Li}$ Jiahou believes that "hybrid learning" refers to the optimal selection and combination of all teaching elements in order to achieve the teaching objectives.

The key to hybrid learning, according to Horne and Steyk in their book Hybrid Learning, is the elements that students can control autonomously during their studies. Otherwise, hybrid learning is no different from teaching online courses to classroom students via electronic whiteboards. This kind of autonomous control can be the control of learning progress that students can freely pause, play back and fast forward the online teaching content. It can also include other types of autonomous control that students can independently choose the online learning time and learn the path of a concept. In short, only when a project contains online learning, and students can at least autonomously control the time, place, path or progress of learning, that just is a hybrid learning.

Different scholars give different concepts according to the emphasis of the study. But from the previous practice, we can think that hybrid learning is to combine the advantages of traditional learning and network learning, to use appropriate teaching methods and techniques to optimize learning, and to form a learning environment that is intersected in class and after class, online and offline.

\section{Theoretical Analysis of Hybrid Learning in Cloud Computing Environment}

\subsection{The constructivism learning view in the field of psychology}

Constructivism holds that learning is not a process of teachers transferring knowledge to students, 
but a process of students constructing knowledge themselves. Teaching should not ignore students' past experience, and should guide students to grow new knowledge and experience from the original knowledge and experience. The view of learning also emphasizes that learning is always carried out in a certain social and cultural environment, and what kind of concept and understanding a person has is always inseparable from the concept and understanding of the learner community in which he is in. The creation of learning community can help learners to construct what they have learned repeatedly from different angles, different situations and different people, thus expanding the learners' knowledge vision and understanding depth.

The inspiration of constructivist learning theory for hybrid learning is that we should pay attention to situational creation, cooperation and conversational construction when designing activities. Construct learning environment that can support learning activities, create learning situation, cooperation and communication space, so that classroom environment and network environment can provide necessary support for learners to cooperate, interact and share. In order to improve the enthusiasm of learners to learn, to complete the construction of meaning.

\subsection{Theory of adult education in the field of pedagogy}

From the perspective of pedagogy, when we say that a person enters adulthood, it means that his cognitive ability and learning ability has reached a mature level, such as the ability to use experience to recognize the surrounding things, and can guide the process of learning by himself. American adult education expert Lindman believes that adult education is "an unauthoritative collaborative discussion and non-formal learning, the main purpose of which is to discover the meaning of experience". Knowles, a famous American adult educator also said that "For adults, their experience is their own, and one of the important purposes of adult education is to help them understand their life experiences and learn from them ".

Therefore, in adult education teaching, teachers need to create an environment in which adult learners can act and participate, encourage them to share their experiences, and propose problem-centred rather than curricular tasks which the teaching will be more effective. Adults are active learners. And by actively thinking and acting on their own initiative and working together with others, it is possible to truly grasp the essence of what they have learned. Only when adult learners truly master the true meaning of what they have learned can they apply the knowledge and skills they have learned to their daily life and work, and change their attitudes and behaviors in dealing with others. And then improve their environment and their way of life.

Adult learning is more heterogeneous, individual learning habits and learning styles have greater differences. In teaching, teachers should respect the differences of adult learners, create as real learning situations as possible, make them have the opportunity to observe, simulate and think, understand their practical principles in specific situations, and make their tacit knowledge explicit, as well as enhance their critical and reflective ability.

\section{Characteristics of Hybrid Learning Based on Cloud Platform in Adult Colleges and Universities}

Based on the analysis of the concepts of cloud computing and hybrid learning, under the guidance of constructivism and adult education theory, adult colleges and universities should have the following characteristics in developing hybrid learning based on cloud platform:

\subsection{Constructing learning community with technology}

The characteristics of adult learning determine the basic principles of organizing adult learning, 
which should be fully considered in adult education teaching. For example, most adults like to work with others that organizing adult learning requires teachers to promote a collaborative process, build learning communities, and support adult learners to share their experiences; A typical classroom is not a learning community, because students are separate or competing with each other. Learning communities emerge when learners share interests and interests, and learning communities grow as learners engage in research and information sharing in order to accomplish a meaningful and important task (harris,1998).

The cloud platform allows schools to build their own data centers, resource sharing, data synchronization, and interactive collaboration capabilities without high costs. At the same time, the cloud platform makes it easy for teachers to meet the teaching needs of grouping students, cooperating learning, exchanging teachers and students and creating learning community without spending no more time to learn computer software and technology. The development of mobile network also enables teachers and students to access the cloud platform through a variety of terminal devices, such as smartphones and tablet PCs, to acquire the necessary learning resources and services anytime and anywhere, and to build a learning community that spans time and space conveniently and quickly.

\subsection{Reconstructing learning space with technology}

The learning space carries the learning activity, the new teaching mode and the learning mode need to rearrange the learning environment in order to promote more positive, real and effective learning. The technology used to reconstruct the learning space needs to translate from teaching and guidance to being controlled by the students themselves, so that they can be called hybrid learning from the perspective of the students, but not from the perspective of the teachers in the classroom which is only use digital tools for teaching. The cloud platform can realize the reconstruction of learning space and adapt to the fragmented learning style of adult learners. For example, build the mobile network learning space based on cloud platform, reconfigure the learning time and space, at the same time, let the students participate in the design and implementation of learning, and provide students with personalized learning experience; The cloud platform supports the creation of a simulated real-world work and social environment that allows adult students to gain experience that has been recognized in the past. At the same time, see their own work results, but also to monitor learning progress and provide feedback.

\subsection{Simplifying the learning process with technology}

At present, professional and application knowledge has gradually become the key content of adult college education and teaching. At the same time, the automation of professional equipment also simplifies the operation procedure and reduces the requirement of operation skills, which make the student's learning process appear the tendency of simplification. For example, learning to drive a car doesn't have to start with designing a car, building an engine, but driving a car into an operational skill, and learning to drive for dozens of hours. And in adult education too much emphasis on the integrity of the knowledge structure, is not conducive to the cultivation of applied talents. Therefore, the application of cloud computing provides a professional teaching platform, which reduces the digital gap and improves the learning efficiency of adult learners. Cloud technology can simplify the learning process and pay more attention to the practicability of knowledge. For example, we use a very simple way that is moving your fingertips and gently pressing, and we can get a lot of information and learn the knowledge at any time and anywhere, so that the learning process of adult learners will be automated. 


\section{Conclusion}

The author also learned that many adult colleges and universities have been actively carrying out the hybrid learning based on cloud platform, this flexible learning method of learning time and space has successfully solved the contradiction of students' work and learning, and has been welcomed by most teachers and students.

\section{References}

[1] Notice of the State Council and the State Council on Issuing the "13th Five-Year Plan" for the Development of National Education [OL].

<http://www.gov.cn/zhengce/content/2017-01/19/content_5161341.htm>

[2] Michael Horn. Hybrid Learning: Promoting Education Revolution with Subversive Innovation [M]. Beijing: Mechanical Industry Press, 2015.

[3] Gao Yuan, Huang Ronghuai. Interpretation and Enlightenment of 2017 New Media Alliance China Higher Education Technology Prospects: Horizon Project Regional Report[J]. Audio-Visual Education Research, 2017, (4): 16-24.

[4] Ma Jixing. Several views on the development trend of adult colleges and universities[J]. Beijing Xuanwu Amateur Hongqi University Journal, 2010, (2): 10-12. 